Research Article

\title{
Double blind randomized comparative study of transdermal fentanyl patch for post operative pain relief in major abdominal surgery as a component of multimodal analgesic therapy
}

\author{
Kalyani Surya Dhanalakshmi Sangineni*, Anuradha Deolalkar, S. C. Parakh, \\ D. Dharma Rajuloo
}

\begin{abstract}
Department of Anaesthesiology, Bhaskar Medical College, Moinabad, Hyderabad, Telangana, India
\end{abstract}

Received: 22 December 2015

Revised: 02 January 2016

Accepted: 08 January 2016

*Correspondence to:

Dr. Kalyani Surya

Dhanalakshmi Sangineni,

Email: sksdhanalakshmi

@hotmail.com

Copyright: () the author(s), publisher and licensee Medip Academy. This is an openaccess article distributed under the terms of the Creative Commons Attribution NonCommercial License, which permits unrestricted noncommercial use, distribution, and reproduction in any medium, provided the original work is properly cited.

\begin{abstract}
Background: There are various methods of alleviating post-operative pain, multimodal analgesia is the recommended practice. Fentanyl patch can also be used in the management of acute postoperative pain. We have done a study to compare the efficacy of fentanyl patch to a placebo patch as a part of multimodal analgesic strategy.

Methods: Forty four patients were randomized into two groups. Groups were named as FP (Fentanyl patch) and P (Placebo). The Patch was placed 10-12 hours before surgery and patient was monitored for 72 hours postoperatively for pain by NRS (Numeric Rating Scale). All the patients received regular Paracetamol and Diclofenac Sodium. Tramadol was given as rescue analgesia if the NRS scale was more than 5. Data was analysed using Windows stat version 9.2 from Indostat services.

Results: There was statistically significant difference in the consumption of Tramadol in patients with FP group (19.44 mg) as compared to $\mathrm{P}$ group (72.22mg) over 72 hours. The Numerical Rating scale was also much lower in the FP group at 8, 16, 24, 32, 40, 48, 56, 64 and 72 hours. Maximum difference in the pain score being at 24 hours for the FP group. No difference in the Sedation, Pruritus, Respiratory depression, Nausea and vomiting scores in the two groups.

Conclusions: Transdermal Fentanyl Patch of $25 \mu \mathrm{g} / \mathrm{hr}$ when applied 10-12 hours before surgery provides effective postoperative pain relief after major abdominal surgery as a part of multimodal analgesia.
\end{abstract}

Keywords: Postoperative pain, Fentanyl patch, Multimodal analgesia

\section{INTRODUCTION}

Acute pain is common in hospitalized patients and inevitable in postoperative patients. Postoperative pain, especially when poorly controlled, may produce a range of detrimental acute (i.e., adverse physiologic responses and chronic effects (i.e., delayed long-term recovery and chronic pain). ${ }^{12}$ Good pain control after surgery is important to prevent negative outcomes such as tachycardia, hypertension, myocardial ischemia, decrease in alveolar ventilation, immobility, deep venous thrombosis and poor wound healing. ${ }^{1}$
Postoperative pain is undertreated and is associated with poorer out-comes, higher costs of care, poor patient satisfaction and increased risk for developing chronic pain syndromes. ${ }^{2}$ Inadequate pain management is a major trigger of the sympathetic nervous system and therefore is viewed as a strong contributor to postoperative stress. ${ }^{10}$ Ischaemic events are well documented in patients following surgery and thought to be indicative of the risk for postoperative morbidity, including serious arrhythmias, myocardial infarction, congestive heart failure, intracranial hemorrhage and death. ${ }^{10,11}$ The stress of surgery and postoperative stress are thought to be contributing factors to ischaemic events. 
Beattie followed 55 patients with 2 or more risk factors for ischemia (coronary artery disease, high blood pressure, history of MI) for 24 hrs following non-cardiac surgery. His results indicate stress as a contributing factor to the early ischaemic events, observed in this study because tachycardia often was observed along with ischaemia. $^{10}$

Other short term consequences of an acute pain include splinting, which can lead to atelectasis and pneumonia, as well as delayed mobilization, which can increase the risk for deep venous thrombosis and subsequent pulmonary embolism.

Although control of postoperative pain is important for recovery, McCaffery and Ferrell showed that over 50\% of surgical patients experienced inadequate pain relief following surgery with negative physiological and psychological consequences. $^{6}$

Chronic pain is a potential adverse outcome from surgery. It is costly to society in terms of suffering and disability. In a review of Perkins et al showed that there was a significant variability in the incidence of chronic pain among surgical procedures (i.e. $3-56 \%$ for cholecystectomy, $0-37 \%$ for inguinal hernia surgery, 11 $57 \%$ for breast surgery). ${ }^{12}$ They concluded that chronic pain after surgery was common as that has been confirmed with another review. ${ }^{15}$ Another conclusion of this study is that the intensity of acute postoperative pain was one of the most striking predictive factor for chronic pain, especially following breast surgery, thoracic surgery and hernia repair. ${ }^{16-19}$

The purpose of this study was to determine the safety and efficacy of Transdermal Fentanyl patch as a component of multimodal analgesia for the control of postoperative pain under conditions of general use in the postsurgical patient population. A non-steroidal anti-inflammatory drug Diclofenac sodium, along with Paracetamol was used as concomitant analgesics with transdermal fentanyl patch (WHO pain ladder). ${ }^{38}$

Multimodal analgesia is the combination of analgesics that act by different mechanisms resulting in additive or synergistic analgesia and lower the total doses of analgesia with reduced side effect. ${ }^{2-4}$ A systematic review determined that when used as a combination NSAIDS and Paracetamol offer superior analgesia compared with either drugs alone. ${ }^{7}$

The transdermal Fentanyl patch (FP) offers the potential benefits of simplicity efficacy and patient acceptance. Fentanyl is soluble in both fat and water with a low molecular weight and high potency, it is ideal for transdermal delivery.
The early transdermal administration of fentanyl was achieved via a reservoir patch. ${ }^{5}$ However, this patch was associated with significant inter-individual variability, so fentanyl matrix patch was developed and designed to be bio-equal to the original reservoir patch with a constant and reliable fentanyl release. Compared to the reservoir patch, the fentanyl in the matrix patch is entirely dissolved in the adhesive, thus opioid dissolution is not required prior to its diffusion through the matrix following application. The matrix patch also has better flexibility and skin conformability, and produces linear fentanyl dose kinetics with negligible dose loading. ${ }^{5,20}$

After initial application, a depot of fentanyl forms in the upper skin layers and serum fentanyl concentrations increase gradually levelling off between $12-24 \mathrm{hrs}$. The steady state serum concentration is reached after $24 \mathrm{hrs}$ and maintained as long as the patch is renewed. ${ }^{5}$

Major surgery, especially intra-abdominal surgeries are associated with severe pain postoperatively which contribute to postoperative respiratory complications due to the splinting of diaphragm and impairment of cough. Good pain relief improves patient compliance for incentive spirometry and improves patient mobilization in the postoperative period. ${ }^{13}$

Ideally best pain relief is achieved by epidural catheters connected to PCEA or infusion pumps, with the attendant technical skills as well as expensive equipment. The other alternative is PCA pumps with morphine infusion, again requiring expensive equipment.

The transdermal fentanyl patch contains a high concentration of fentanyl and according to the pharmaceutical company is indicated for management of persistent moderate to severe pain. Contraindications include management of acute pain. ${ }^{22}$

The purpose of this study is to test the efficacy of the Transdermal fentanyl patch in ameliorating severe pain in major surgery in the first three days postoperatively. It is not routinely used for control of acute postoperative as its onset of action is slow, taking as long as 12 to 15 hours for good pain relief. To offset this disadvantage the patch was applied 10 hours prior to surgery. For the management of postoperative pain, it may be desirable to apply transdermal fentanyl patch several hours before completion of surgery so that the MEC (Minimum effective concentration) can be achieved prior to or concomitant with the end of surgery. Keeping in mind this pharmacokinetic effect, the transdermal patch was placed around $10 \mathrm{hrs}$ before the start of surgery, so that the effective levels of fentanyl are present by the end of surgery. In our study the patients with FP had significantly lower Numeric Rating Scale and had significantly lower Tramadol consumption 
This study is based on the premise that FP $(25 \mu \mathrm{g})$ applied 10 to 12 hours before surgery would provide better pain relief for 72 hours compared to a placebo.

The primary outcome would be the difference in consumption of Tramadol and secondary outcome would be the incidence of complication of nausea and vomiting, sedation, pruritus and respiratory depression.

\section{METHODS}

The study was approved by ethics committee of Bhaskar Medical College. The Study is prospective randomized double blind controlled trial. 44 patients were included in the study. 22 patients were allotted to the FP group and 22 patients to the $\mathrm{P}$ group.

The patches were numbered and put into a box and the duty anaesthesiologist took the patch and just entered the number on the anaesthesia sheet totally blinded to the type of patch. The only person who had a list of the type of patch was the theatre secretary with the master list with the numbers given to each patch. There was no physical difference between the patches to give visual clues regarding the identity of the patch.

We included patients between 20 to 70 years scheduled for major surgery having an ASA physical status 1 to 2 .

\section{Exclusion criteria}

1. ASA 3-4

2. History of drug abuse

3. Emergency

4. Extremes of age

5. Pregnancy

The Fentanyl patch used was Fen-Touch $25 \mathrm{mcg} / \mathrm{hr}$ by Sparsha Pharma International Private limited. They also provided the placebo patches.

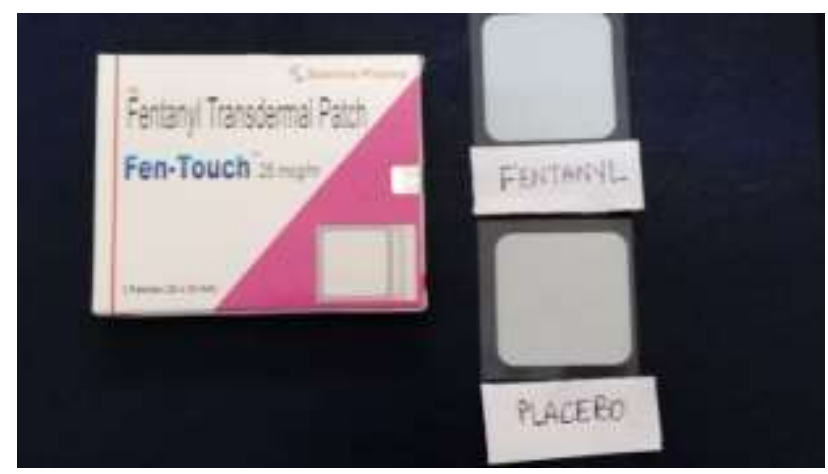

Figure 1: Fen-Touch (Fentanyl patch).
The patch was applied 10 to 12 hours prior to the surgery by the duty anaesthesiologist who just placed the patch and fixed with plaster to prevent displacement and also labelled it with date and time of affixing. The patches were numbered and taken from a box containing both the placebo and the TDF. Only the theatre secretary had the list containing numbers designated to the placebo and was never involved further than that.

General anaesthesia was given to all patients using standardised drugs as in Fentanyl 2 micrograms per kg, inducing dose of Thiopentone $(3-5 \mathrm{mg} / \mathrm{kg})$, intubating dose of Vecuronium $(0.1 \mathrm{mg} / \mathrm{kg})$ and Tramadol $(1.5$ $\mathrm{mg} / \mathrm{kg}$ ). All patients received Diclofenac Sodium (100 $\mathrm{mg}$ ) and Paracetamol (1 gm), per rectal suppositories after induction.

All were monitored intraoperatively with ECG, $\mathrm{SaO}_{2}$, NIBP, ETCO ${ }_{2}$ maintained with $\mathrm{O}_{2}$ and $\mathrm{N}_{2} \mathrm{O}$ with Sevoflurane, reversed with Neostigmine $(0.05 \mathrm{mg} / \mathrm{kg})$ and glycopyrolate $(0.02 \mathrm{mg} / \mathrm{kg})$ and monitored in the recovery room for $2 \mathrm{hrs}$ post operatively.

From the recovery room, the patients were shifted to the post-operative ward, and patients were monitored by a nurse who was blinded to the kind of patch that had been applied to the patient. From the time of arrival details regarding the vitals and specifically pertinent to the study that is NRS score at rest, sedation score, nausea and vomiting score and pruritus were recorded every four hours.

Patients received regular Diclofenac and Paracetamol and, Tramadol was given for rescue analgesia.

The following scores were used to monitor for sedation, pruritus, nausea and vomiting and respiratory depression.

\section{Ramsay sedation scores}

$1=$ awake

$2=$ drowsy

$3=$ sleepy but easy to arouse to verbal commands

$4=$ sleepy but rousable to moderate stimulation

$5=$ unconscious

\section{Nausea and vomiting scores}

$0=$ none

$1=$ mild $(1-2)$

$2=$ moderate

$3=$ severe

\section{Pruritus}

Present +1

Absent 0 


\section{Respiratory depression}

Respiratory rate less than 8 .

Acute hypoxic event (Oxygen saturation less than 90\%).

\section{Statistical analysis}

Data was analysed using Windostat version 9.2 from Indostat Services.

Age weight, duration of surgery and analgesic consumption were compared using unpaired $\mathrm{T}$ Test and Mann Whitney test. Percentage and frequencies of patients were compared using chi square test. A repeated measure ANOVA was used to compare the other variables. A p value of $<0.05$ was considered statistically significant. The dose of Tramadol used was analysed using Mann-Whitney Test.

\section{RESULTS}

There was no statistical difference in the two groups regarding age, duration of surgery and weight of the patient (Table 1).

Table 1: Demographic data of the patients' age, weight and duration of surgery mean and $p$ values.

\begin{tabular}{|lll|l|}
\hline & Fentanyl patch & Placebo & P value \\
\hline Age & 43.611 & 36.55 & 0.08 \\
\hline $\begin{array}{l}\text { Weight of } \\
\text { patient }\end{array}$ & 52.22 & 52.778 & 0.84 \\
\hline $\begin{array}{l}\text { Duration of } \\
\text { surgery }\end{array}$ & 163.33 & 171.944 & 0.438 \\
\hline
\end{tabular}

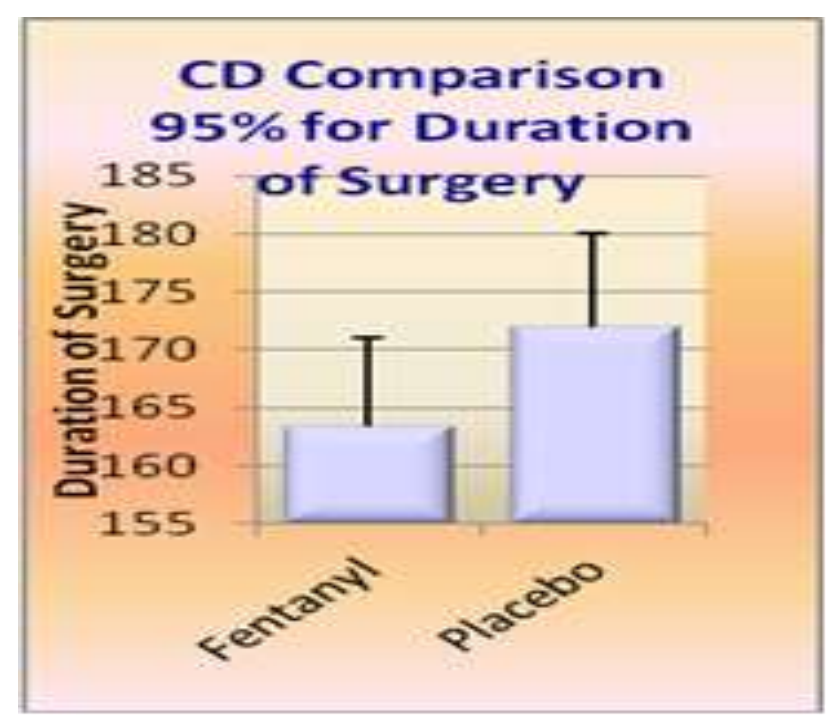

Figure 2: Duration of surgery.
Significant statistical difference regarding consumption of Tramadol was seen. Patients with FP Consumed less Tramadol (19.44 mg) than patients with the placebo patch (72.22).

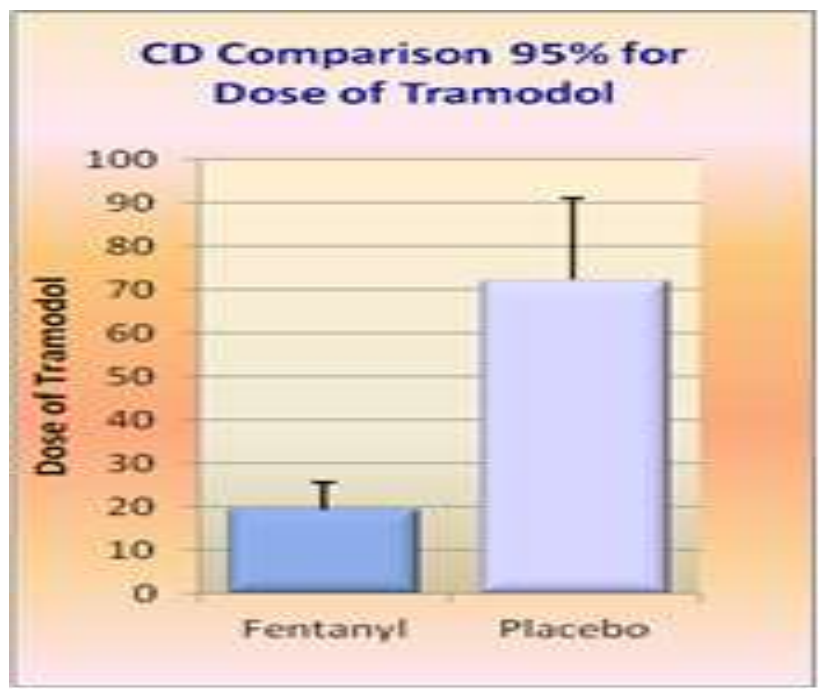

Figure 3: Dose of tramadol.

The statistical difference as regards the dose of Diclofenac in patients with TDF (316.11) and patients with placebo (345.833) significantly different, as despite protocol, of regular NSAIDS, these patients required much less of diclofenac sodium. The dose of Paracetamol in FP group was 4.864 and in the placebo group was 5.227 , the $\mathrm{p}$ value being 0.1503 , i.e. not significantly different in both groups.

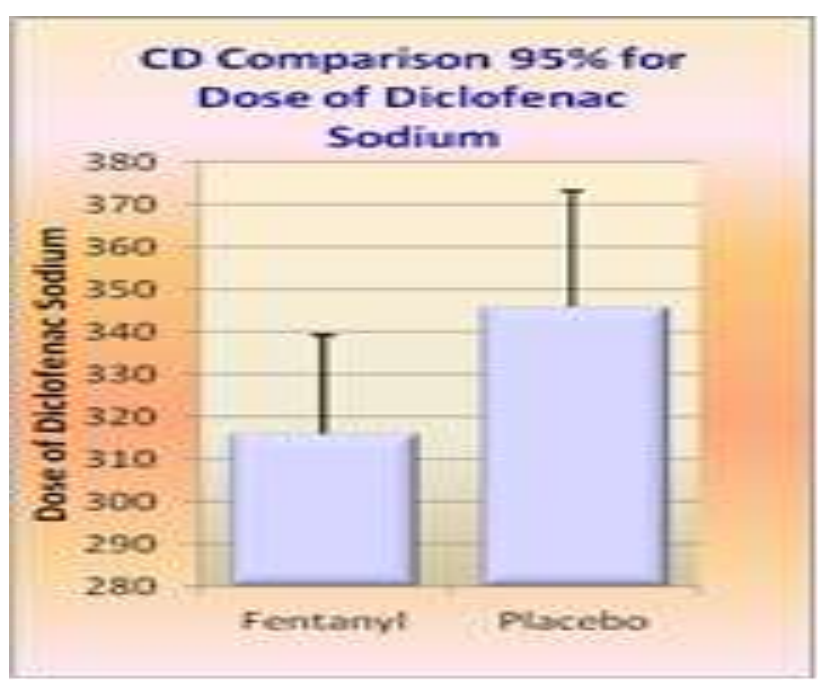

Figure 4: Dose of diclofenac sodium in fentanyl group and placebo group. 


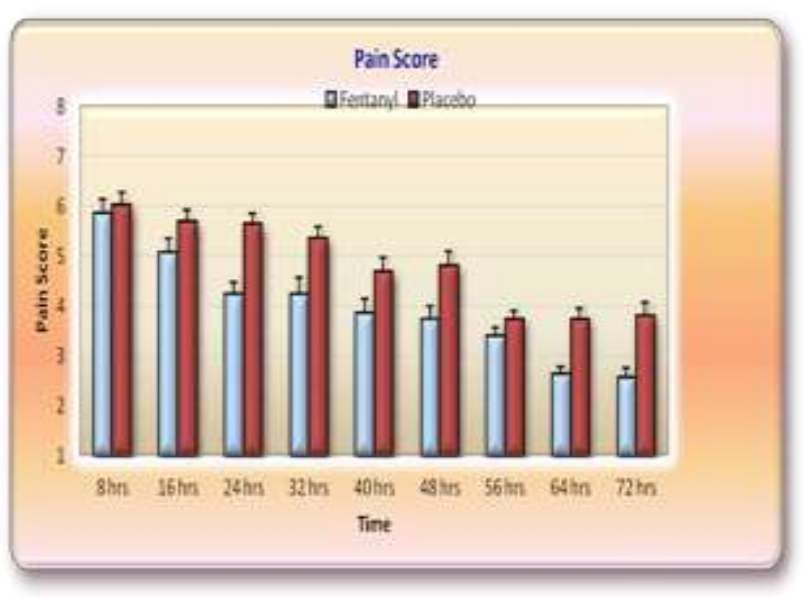

Figure 5: Pain scores over 72 hours of FP and placebo.

There was no significant difference between the two groups in the hemodynamic parameters (systolic blood pressure, diastolic blood pressure and Heart rate) throughout the period of the study. There were no patients in the post-operative period whose saturations dropped to less than $95 \%$ during the study period in either group. Also no patients went into respiratory depression $(\mathrm{RR}<8)$.

Regarding the adverse effects of nausea and vomiting four patients in the FP group and two patients in the placebo group had vomiting which was not statistically significant difference. There were no cases with pruritus in either group. There were also no significant differences in sedation scores in either group.

The other very significant finding was the pain scores being much lower in the TDF group at 8, 16, 24, 32, 40, 48, 56, 64, $72 \mathrm{hrs}$. The maximum difference in pain scores being at $24 \mathrm{hrs}$ (4.22) for the TDF group and (5.611) of the placebo group. Although at any point of time patients with TDF had lower pain scores than the placebo group.

\section{DISCUSSION}

Multi modal analgesia is defined as the simultaneous use of different classes or modes of analgesia that modulate different pathways and receptors in order to provide superior pain control.

Multimodal analgesia captures the effectiveness of individual agents in optimal dosages that maximize efficacy and attempts to minimize side effects from one analgesic (mainly opioids). This important concept employs the theory that agents with different mechanisms of analgesia may have synergistic effects in preventing or treating acute pain when used in combination.
Multimodal analgesia provides several types of benefits to postoperative patients. ${ }^{25-28}$ Firstly, use of agents with different analgesic mechanisms can result in synergistic effects and thereby produce greater efficacy. ${ }^{27}$ Secondly the synergism between these agents allows the use of lower doses of each respective agent, thereby limiting the adverse effects, particularly when these regimens allow for lower doses of opioids. ${ }^{25,26}$ These actions, in turn may facilitate earlier mobilization and rehabilitation after surgery, earlier transition to the outpatient setting, and decreased costs of care. ${ }^{25}$

Our study is based on this premise and we are studying the effectiveness of incorporating the application of low dose transdermal fentanyl patch into the multimodal analgesia model and its effectiveness in achieving maximum patient comfort with minimum complications.

Some studies have reported that FP did not significantly relieve postoperative pain. In our study, we found FP to significantly reduce numeric rating scores at all durations post operatively for up to $72 \mathrm{hrs}$ as well as the total dose of Tramadol consumed 19.44 by the FP group and 72.222 by the placebo group as can be seen in the Table 2 , as well as a significant reduction in Diclofenac sodium consumption also.

In the study by Rowbotham DJ et al, FP was placed just before or within $2 \mathrm{hrs}$ of surgery not allowing for the plateauing of the serum levels to take place, ${ }^{29}$ therin may be accounting for inadequate pain relief. Sevarino et al found significantly better analgesia with $50 \mathrm{ug} / \mathrm{hr}$ fentanyl patches as compared to the $25 \mu \mathrm{g} / \mathrm{hr}$ patch, but the patch was place only one hour before the start of surgery and was the sole analgesic used. ${ }^{30}$ We have used the $25 \mu \mathrm{g} / \mathrm{hr}$ fentanyl patch and found it to provide adequate pain relief.

Osipova et al studied the effect of FP for prevention and treatment of postoperative pain syndrome, in extensive thoracoabdominal oncological surgery and concluded that FP in the early post-operative period may prevent acute opioid tolerance and hyperalgesia, underscoring the benefit of their use in multimodal postoperative analgesia with NSAID's further corroborating our findings. ${ }^{31}$

One also has to consider the potential threat to life by misuse of transdermal fentanyl patch, and take measures to educate patients, and be vigilant to the potential misappropriation. Mark D Reeves et al, reported the transdermal fentanyl patch contents being used intravenously by a $35 \mathrm{yr}$. old woman with a history of intravenous drug abuse leading to her untimely death. ${ }^{32}$ Edinboro et al reported a case, in which an 83 year old female with terminal cancer was found with three 100 microgram per hour transdermal fentanyl patches, death was caused by fentanyl overdose. ${ }^{33}$ 
In our study we have used $25 \mu \mathrm{g} / \mathrm{hr}$ Fentanyl patch, a small dose, with a background of multimodal analgesia wherein a continuous analgesia with a low dose fentanyl was combined with regular medication of Diclofenac sodium and Paracetamol. The FP group of patients were comfortable and the side effects were minimal and we did not have any increased sedation or any case of respiratory depression. The limitation of the study being the small sample size. Several studies have been done to reiterate the efficacy of the FP in postoperative pain relief.

Table 2: Summary of the mean values of duration of surgery, dose of tramadol, dose of diclofenac sodium, weight and pain scores at 8, 16, 24, 32, 40, 56, 64 and 72 hrs.

\begin{tabular}{|c|c|c|c|c|c|c|c|c|c|c|}
\hline Variable & Fentanyl & $\begin{array}{l}\text { Std. } \\
\text { Err. }\end{array}$ & $\begin{array}{l}\text { Std. } \\
\text { Dev. }\end{array}$ & Placebo & $\begin{array}{l}\text { Std. } \\
\text { Err. }\end{array}$ & $\begin{array}{l}\text { Std. } \\
\text { Dev. }\end{array}$ & $\begin{array}{l}\text { T } \\
\text { Test }\end{array}$ & Probability & $\begin{array}{l}\text { Mann } \\
\text { Whitney }\end{array}$ & Probability \\
\hline $\begin{array}{l}\text { Duration } \\
\text { of Surgery }\end{array}$ & $163.33 \pm$ & 7.616 & 32.313 & $171.944 \pm$ & 7.916 & 33.587 & 0.784 & 0.439 & 136.000 & 0.212 \\
\hline $\begin{array}{l}\text { Dose of } \\
\text { Tramadol }\end{array}$ & $19.444 \pm$ & 5.912 & 25.082 & $72.222 \pm$ & 18.622 & 79.005 & 2.701 & $0.011 *$ & 54.000 & $0.000 * * *$ \\
\hline $\begin{array}{l}\text { Dose of } \\
\text { Diclofenac } \\
\text { Sodium }\end{array}$ & $316.111 \pm$ & 22.950 & 97.371 & $345.833 \pm$ & 27.210 & 115.444 & 0.835 & 0.410 & 105.000 & $0.037 *$ \\
\hline Weight & $52.222 \pm$ & 1.931 & 8.193 & $52.778 \pm$ & 2.006 & 8.510 & 0.200 & 0.843 & 153.000 & 0.395 \\
\hline $\begin{array}{l}\text { Pain score } \\
8 \mathrm{hrs}\end{array}$ & $5.833 \pm$ & 0.283 & 1.200 & $6.00 \pm$ & 0.256 & 1.085 & 0.437 & 0.665 & 126.000 & 0.132 \\
\hline $\begin{array}{l}\text { Pain Score } \\
16 \text { hrs }\end{array}$ & $5.056 \pm$ & 0.274 & 1.162 & $5.667 \pm$ & 0.243 & 1.029 & 1.671 & 0.104 & 109.000 & $0.049 *$ \\
\hline $\begin{array}{l}\text { Pain Score } \\
24 \mathrm{hrs}\end{array}$ & $4.222 \pm$ & 0.236 & 1.003 & $5.611 \pm$ & 0.216 & 0.916 & 4.337 & $0.000 * * *$ & 36.000 & $0.000 * * *$ \\
\hline $\begin{array}{l}\text { Pain Score } \\
32 \mathrm{hrs}\end{array}$ & $4.222 \pm$ & 0.329 & 1.396 & $5.333 \pm$ & 0.229 & 0.970 & 2.774 & $0.009 * *$ & 61.000 & $0.000 * * *$ \\
\hline $\begin{array}{l}\text { Pain Score } \\
40 \mathrm{hrs}\end{array}$ & $3.833 \pm$ & 0.283 & 1.200 & $4.667 \pm$ & 0.280 & 1.188 & 2.093 & $0.044 *$ & 100.00 & $0.025^{*}$ \\
\hline $\begin{array}{l}\text { Pain Score } \\
48 \mathrm{hrs}\end{array}$ & $3.722 \pm$ & 0.253 & 1.074 & $4.778 \pm$ & 0.298 & 1.263 & 2.701 & $0.011 *$ & 69.000 & $0.001 * * *$ \\
\hline $\begin{array}{l}\text { Pain score } \\
56 \mathrm{hrs}\end{array}$ & $3.389 \pm$ & 0.164 & 0.698 & $3.722 \pm$ & 0.158 & 0.669 & 1.463 & 0.153 & 98.000 & $0.022 *$ \\
\hline $\begin{array}{l}\text { Pain Score } \\
64 \mathrm{hrs}\end{array}$ & $2.611 \pm$ & 0.164 & 0.698 & $3.722 \pm$ & 0.211 & 0.895 & 4.154 & $0.000 * * *$ & 42.000 & $0.000 * * *$ \\
\hline Pain Score & $2.556 \pm$ & 0.185 & 0.784 & $3.778 \pm$ & 0.263 & 1.114 & 3.806 & $0.001 * * *$ & 47.000 & $0.000 * * *$ \\
\hline
\end{tabular}

Lehman and Desio et al have found that the use of transdermal fentanyl patch provided similar postoperative analgesia with less parenteral analgesics in patients who received transdermal fentanyl preoperatively than in control patients. ${ }^{34}$ Reinhart \& Goldberg et al, concluded that transdermal fentanyl delivery system plus ketorolac intramuscular was more effective in controlling postoperative pain than ketorolac alone. $^{35}$

Merivirta R \& Aarimaa et al published that a Fentanyl patch delivering $12 \mu \mathrm{g} / \mathrm{hr}$ offers an easy and safe treatment option as a part of multimodal analgesia with a few adverse effects in the treatment of postoperative pain in a carefully selected patient group after arthroscopic shoulder surgery. ${ }^{36}$
Sathitkarnmee $\mathrm{T} \&$ Tribuddharat $\mathrm{S}$ found that $50 \mu \mathrm{g} / \mathrm{hr}$ transdermal fentanyl patch applied 10-12 hrs before surgery can effectively and safely decrease postoperative Morphine consumption and pain scores during the first 48 hrs after Total Knee Arthroplasty (TKA). ${ }^{37}$

Samy et al have corroborated our findings that transdermal Fentanyl patch $50 \mu \mathrm{g} / \mathrm{hr}$ is effective, noninvasive and can be used safely for postoperative pain relief in major abdominal surgery with minimal acceptable side effects. ${ }^{39}$ In our study all the cases with Transdermal fentanyl Patch were haemodynamically stable. There was no sedation, pruritus or respiratory depression in the post-operative period. Nausea and vomiting occurred in $22 \%$ of the patients but was not statistically significant. The use of Diclofenac Sodium 
and Paracetamol on a fixed time basis with the transdermal fentanyl patch made the patient more comfortable and reduced the attendant side effects of opioids. We would like to restate that FP of $25 \mu \mathrm{g} / \mathrm{hr}$ as a part of multi modal analgesic strategy is effective and safe under close observation. Though there are no actual measures for this our patient population were a part of the rural group and used to hard labour, whether this contributed to their tolerance to pain is an unquantifiable factor.

The incidence of respiratory depression sedation and nausea and vomiting is higher in patches releasing 75 $\mu \mathrm{g} / \mathrm{hr}$ as seen by Sevarino et al further underlining the fact that the side effects are very much dose dependent and by using a smaller dose would bring down incapacitating nausea and vomiting, the discomfort of pruritus and life threatening respiratory depression. Still, till further large scale studies are done, FP can be used for major surgeries for pain relief in the opioid naïve patients under close monitoring.

\section{CONCLUSION}

A transdermal Fentanyl Patch of $25 \mu \mathrm{g} / \mathrm{hr}$ when applied 10-12 hrs before surgery provides effective, non-invasive postoperative pain relief after major abdominal surgery, as a part of multimodal analgesia. The incidence of respiratory depression, sedation, nausea and vomiting was not significantly increased from the placebo group. Good postoperative pain relief makes mobilization easier as well as compliance to spirometry better, thereby reducing further complications. Further studies are needed to see the safety profile of FP in patients with coexisting diseases especially respiratory disorders.

The advantages of FP are numerous, foremost being the ease of administration by adhesion to skin, no risk of infection, easy availability, specially trained personnel are not needed (as for epidural insertion) and costs less than a PCA pump while providing a steady release of fentanyl. All these effects are may be offset by the disadvantage that the onset of pain relief is $10-15 \mathrm{hrs}$ away from the time of placement. To conclude Fentanyl Patch $25 \mu \mathrm{g} / \mathrm{hr}$ can be used to alleviate postoperative pain in major abdominal surgeries as a component of multimodal pain strategy under close observation.

Funding: No funding sources Conflict of interest: None declared

Ethical approval: The study was approved by the Institutional Ethics Committee

\section{REFERENCES}

1. Vadivelu N, Mitra S, Narayan D. Recent advances in postoperative pain management. Yale J Biol Med. 2010;83(1):11-25.

2. Canet J, Mazo V. Postoperative pulmonary complications. Minerva Anestesiologica. 2010;76(2):138-4.

3. Kehlet H, Dahl JB. The value of multimodal or balanced analgesia in the postoperative pain treatment. Anesth Analg. 1993;77:1048-56.

4. Kehlet H, Dahl JB. Anaesthesia, surgery and challenges in postoperative recovery. Lancet. 2003;362:1921-8.

5. Margetts L, Sawyer R. Continuing Education in Anaesthesia, Critical Care \& Pain. 2007;7(5).

6. McCaffery M, Ferrell B. Nurses 'knowledge of pain assessment and management: how much progress have we made? J Pain Symptom Manage. 1997;14(3):175-88.

7. Ong CK, Seymour RA, Lirk P, Merry AF. Combining paracetamol (acetaminophen) with nonsteroidal antiinflammatory drugs: a qualitative systematic review of analgesic efficacy for acute postoperative pain. Anesth Analg. 2010;110(4):1170-9.

8. Sathyan G, Guo C, Sivakumar K. Evaluation of the bioequivalence of two transdermal fentanyl systems following single and repeat applications. Curr Med Res Opin. 2005;21(12):1961-8.

9. Davis MP. Management of cancer pain:focus on new opioid analgesic formulations. Am $\mathbf{J}$ Cancer. 2006;5(3):171-82.

10. Beattie WS, Buckley DN, Forrest JB. Epidural morphine reduces risk of postoperative myocardial ischaemia in patients with cardiac risk factors. Can J Anasth. 1993:40(6):532-44.

11. Basali A, Mascha EJ, Kalfas I, Schubert A. Relation between perioperative hypertension and intracranial hemorrhage after craniotomy. Anaesthesiology 2000:93(1):48-54.

12. Perkins FM, Kehlet H. Chronic pain as an outcome of surgery. A review of predictive factors. Anesthesiology. 2000;93(4):1123-33.

13. Culp WC Jr, Beyer EA. Preoperative inspiratory muscle training and postoperative complications. JAMA. 2007:297(7)697-8.

14. Agnelli G, Bolis G, Capussoti L, Tonelli F. A clinical outcome based prospective study on venous thromboembolism after cancer surgery: The @ RISTOS project. Ann Surg. 2006;243(1):89-95.

15. Camann W, Abouleish A, Eisenach J, Hood D. Intrathecal sufentanil and epidural bupivacaine for labor analgesia: dose-response of individual agents and in combination. Reg Anesth Pain Med. 1998;23(5):457-62. 
16. Elia N, Lysakowski C, Tramèr MR. Does multimodal analgesia with acetaminophen, nonsteroidal anti-inflammatory drugs, or selective cyclooxygenase-2 inhibitors and patient-controlled analgesia morphine offer advantages over morphine alone? Anesthesiology. 2005;103(6):1296-304.

17. Carli F, Mayo N, Klubien K, Schricker T. Epidural analgesia enhances functional exercise capacity and health-related quality of life after colonic surgery: results of a randomized trial. Anesthesiology. 2002;97(3):540-9.

18. Viscusi ER, Reynolds L, Chung F, Atkinson LE. Patient-controlled transdermal fentanyl hydrochloride vs intravenous morphine pump for postoperative pain: a randomized controlled trial. JAMA. 2004;17:1333-41.

19. Birnbach DJ, Johnson MD, Arcario T, Datta S. Effect of diluent volume on analgesia produced by epidural fentanyl. Anesth Analg. 1989;68(6):808-10.

20. Patel D, Chaudhary SA, Parmar B, Bhura N. Transdermal delivery System:A Review. The Pharma Journal.com. 2012;1(4).

21. Bajaj S, Whiteman A, Brandner B. Transdermal drug delivery in pain management. BJA. 2011;11(2):3943.

22. Fen-Touch Company Insert,Sparsha Pharma International Pvt. Limited.www.sparsha.com. Accessed July 2, 2014.

23. Gottschalk A, Smith DS. New concepts in Acute Pain therapy: Preemptive analgesia. Am Fam Physician. 2001;63(10):1979-84.

24. Woolf CJ, Chong MS. Preemptive Analgesia-treating postoperative pain by preventing the establishment of central sensitization. Anaes Analge. 1993;77(2):3627.

25. Richmond CE, Bromley LM, Woolf CJ. Preoperative morphine preempts postoperative pain. Lancet. 1993;342(8863):73-5.

26. Joshi GP, Ogunnaike BO. Consequences of inadequate postoperative pain relief and chronic persistent postoperative pain. Anaesiol Clin North Am. 2005;23(1):21-36.

27. White PF. Multimodal Analgesia;its role in preventing postoperative pain. Curr Opin Investig Drugs. 2008;9(1):76-82.

28. Kehlet H, Wilmore DW. Multimodal strategies to improve surgical outcome. Am J Surg. 2002;183(6):630-41.

29. Rowbotham DJ, Wyld R, Peacock JE, Duthie DJ, Nimmo WS. Transdermal fentanyl for the relief of pain after upper abdominal surgery. $\mathrm{Br} \mathrm{J}$ Anesth. 1989;63:56-9.
30. Sevarino FB, Paige D, Sinatra RS. Postoperative analgesia with parenteral opioids: does continuous delivery utilizing a transdermal opioid preparation affect analgesic efficacy or patient safety? J Clin Anesth. 1997;9(3):173-8.

31. Osipova NA, Petrova VV, Lastukhin AV, Kudriavtsev SB, Vashakmadze LA, Khomiakov VM. Prevention and treatment of postoperative pain syndrome in extensive thoracoabdominal oncological surgery. Anesteziol Reanimatol. 2010;(3):29-33.

32. Reeves MD, Ginifer CJ. Fatal intravenous misuse of Transdermal Fentanyl Patch. Medical Journal of Australia. 2002;177(10):552-3.

33. Edinboro LE, Poklis A, Trautman D. Fatal Fentanyl intoxication following excessive transdermal application. J Forensic Sci. 1997;42(4):741-3.

34. Lehman LJ, Desio JM, Radvany T, Bikhazi GB. Transdermal Fentanyl in postoperative pain. Reg Anaes. 1997:22(1):24-8.

35. Reinhart DJ, Goldberg ME, Roth JV, Dua R, Nevo I, Klein KW. Transdermal fentanyl system plus im ketorolac for the treatment of postoperative pain. Canadian Journal of Anaesthesia. Can J Anaesth. 1997;44(4):377-84.

36. Merivirta R, Äärimaa V, Aantaa R, Koivisto M, Leino K, Liukas A. Postoperative Fentanyl Patch versus subacromial Bupivacaine infusion in arthroscopic shoulder surgery. Arthroscopy. The Journal of Arthroscopic and related surgery. Arthroscopy. 2013;29(7):1129-34.

37. Sathitkarnmanee T, Tribuddharat S, Noiphitak K, Theerapongpakdee S, Pongjanyakul S. Transdermal fentanyl patch for postoperative analgesia in total knee arthroplasty: a randomized double-blind controlled trial. Journal of Pain Research. 2014;7:449-54.

38. WHO. WHO's cancer pain ladder for adults. 2009. http://www.who.int/cancer/palliative/painladder/en. Accessed July 2, 2014.

39. Samy AA, Mostafa MG, Mostafa MAM. Efficacy and Safety of Transdermal Fentanyl Patches on Postoperative Pain Relief After Major Abdominal Surgery. J Am Sci. 2012;8(6):417-24.

Cite this article as: Sangineni KSD, Deolalkar A, Parakh SC, Dharma Rajuloo D. Double blind randomized comparative study of transdermal fentanyl patch for post operative pain relief in major abdominal surgery as a component of multimodal analgesic therapy. Int J Basic Clin Pharmacol 2016;5:13-20. 